Ensino

\title{
Utilizando os conhecimentos prévios sobre célula de estudantes de um curso de enfermagem como ponto de partida do planejamento de ensino
}

\author{
Using nursing students' previous knowledge about cell as starting point \\ of teaching planning
}

\section{Lidianne Salvatierra' ${ }^{(10}$}

' Universidade Estadual de Roraima, Boa Vista, RR, Brasil

\begin{abstract}
RESUMO
O conhecimento prévio do estudante é extremamente importante para a aprendizagem de um novo conteúdo, e o diagnóstico desse conhecimento pode ajudar no planejamento de ensino. Neste artigo foi utilizado o método de livre associação de palavras para inventariar o conhecimento prévio dos alunos para construir um planejamento de ensino da disciplina de Citologia. Assim, 60 alunos calouros de um curso de enfermagem, durante a primeira aula de Citologia, foram solicitados a citarem 15 termos sobre o tema "célula". A análise inicial verificou que os alunos possuíam um conhecimento prévio adequado com 210 termos (123 termos centrais e 87 termos derivados) e 752 citações levantadas ao todo. Os termos foram categorizados em cinco categorias e foram utilizados como referência na construção do planejamento de ensino buscando o conhecimento sistematizado a partir do senso comum entre os termos e frequências dessas categorias. A estratégia de ensino buscou a ativação do conhecimento prévio, nivelamento conteudinal e abordagem dos temas de forma contextualizada com o cotidiano do aluno. A estratégia permitiu a maior assimilação do conteúdo, motivação e participação das aulas pelos alunos. Adicionalmente, uma ficha de avaliação diagnóstica inicial foi formulada para a coleta de termos livres associados a fim de facilitar a organização e análise dos dados de conhecimentos prévios pelo professor.
\end{abstract}

Palavras-chave: Teste de associação livre de palavras; Estrutura cognitiva; Processo de aprendizagem

\section{ABSTRACT}

The prior knowledge of the student is extremely important for learning new content, and the diagnosis of such knowledge can assist teacher's education planning. In this article the free association of words method was carried out to survey the students' previous knowledge in order to formulate a Cytology lesson plan. Thus, 60 freshman nursing students were asked to provide 15 words about the topic "Cell" during their first Cytology class. The initial analysis found that students had adequate prior knowledge with 210 terms (123 central terms and 87 derived terms) and 752 citation obtained. All terms were categorized into eleven categories and were used as references to construct a teacher education planning guide aiming a systematized knowledge by the common sense between the terms and frequencies of these categories. 
The teaching strategy sought the activation of student's prior knowledge, content leveling and contextualized learning by focusing on concrete applications in students' everyday life. The strategy allowed for greater assimilation of the content, motivation and participation in class by the students. In addition, an initial diagnostic evaluation form to collect associated free terms was formulated to facilitate the organization and analysis of prior knowledge data by the teacher.

Keywords: Free word association test; Cognitive structure; Learning process

\section{INTRODUÇÃO}

A citologia, disciplina básica para estudos da área da saúde, é pré-requisito para o entendimento da complexidade da célula e posterior compreensão sobre a organização dos tecidos e funções fisiológicas do organismo. Na enfermagem, a citologia representa a base para o estudo da fisiologia normal e processos patológicos da origem e evolução de diferentes enfermidades. Porém, apesar da disciplina ser ministrada na academia, a formação dos conceitos básicos surge ainda nos ensinos de Educação Básica. Estes conceitos básicos são descritos por Vygotsky (2010) como parte de conhecimentos científicos.

Os conhecimentos científicos se diferenciam de conhecimentos espontâneos por serem formados a partir de um aprendizado sistematizado, usualmente do geral para o particular, com a abordagem de exercícios lógicos e abstratos, possuem boa generalização, estão relacionados à experiência transmitida intencionalmente por um mediador, e são pressupostos para a consciência, a generalização e para a sistematização de conceitos espontâneos (VYGOTSKY, 2010).

Com relação ao percurso da abordagem do tema em âmbito escolar e observando a recém-estabelecida Base Nacional Comum Curricular (BNCC) do Ensino Fundamental, a citologia deve começar a ser abordada no sexto ano dentro da unidade temática "Vida e Evolução". A unidade tem como objetivo reconhecer a célula como singularidade da vida, explicando a organização básica das células e seu papel como unidade estrutural e funcional dos seres vivos, a fim de compreender que os organismos são uma complexa organização de sistemas com diferentes níveis de organização (BRASIL, 2016). Nos oitavo e nono anos devem ser abordados os 
mecanismos reprodutivos e hereditariedade, respectivamente, como base para processos celulares mais complexos (BRASIL, 2016).

Os Parâmetros Curriculares Nacionais (PCN) para o Ensino Médio evocam a essencial construção do conceito sistematizado de célula passando pela Teoria Celular e finalizando no entendimento da relação entre os processos celulares e as tecnologias, como as utilizadas na medicina por exemplo (BRASIL, 2006).

Assim, é esperado que os alunos ao final do percurso da Educação Básica demonstrem a compreensão da célula como um sistema organizado que realiza reações químicas vitais, que interage constantemente com o ambiente interno, e também que possam distinguir entre os tipos fundamentais de células, organelas e suas funções específicas (BRASIL, 2006).

Quando o aluno se torna um acadêmico da área da saúde, o tema celular é novamente apresentado de forma mais aprofundada, específica, interdisciplinarizada e contextualizada para a sua área de formação. Dessa forma, é fundamental que o acadêmico apresente uma pré-formação básica e científica sobre os conceitos citológicos. Sabe-se, porém, que em uma sala de aula os alunos apresentam diferentes níveis de bagagem conteudinal pré-acadêmica e é fundamental que o professor desenvolva suas aulas ao início de cada tema com o objetivo de promover o nivelamento dos alunos para poder ministrar o conteúdo desejado em amplo espectro. Assim, o levantamento de conhecimento prévio dos estudantes pelos professores deve ser entendido como um exercício de aproximação de conhecimentos já adquiridos com os objetivos de aprendizagem dos conhecimentos novos (SALVATIERRA, 2019).

Uma forma de verificação da bagagem conteudinal é o levantamento dos elementos conhecidos - conhecimento prévio - sobre um determinado tema, o que serve de referência para o professor como um diagnóstico inicial para o seu planejamento de ensino e para análise da construção de novos conceitos. O conhecimento prévio pode ser tanto quantificado quanto qualificado e tem reflexo na 
aquisição de um novo conhecimento e no desenvolvimento de uma rede complexa de saberes integrados (AUSUBEL, 1990).

Na perspectiva da Teoria Histórico-Cultural de Vygotsky $(1991,2010)$, estudos envolvendo a construção de conceitos científicos possibilitam a melhor compreensão sobre as formas de concepção dos alunos fornecendo material para que o professor possa contribuir no processo de formação de pensamentos complexos, ressignificações e correlações multidisciplinares (CASTRO et al., 2016a).

Atualmente, o professor dispõe de diversos métodos para sondagem dos saberes prévios dos alunos como construção de portfólios, relatórios, mapas conceituais, pré-testes, roda de discussões, debates e outros. A maioria das pesquisas de levantamento de conhecimentos prévios utilizam métodos de coleta de dados de estruturas cognitivas através de conceitos (respostas completas), porém o uso de levantamento através de citações de palavras ou termos é uma alternativa rápida e eficiente para avaliação diagnóstica (GILBERT et al., 1998a,b; GILBERT; BOULTER, 2000). Assim, o presente trabalho investigou os conhecimentos prévios a partir da livre associação de palavras de estudantes do primeiro ano de enfermagem sobre "Célula" a fim de facilitar o planejamento de ensino.

\section{ESTUDOS ACERCA DOS CONHECIMENTOS PRÉVIOS SOBRE CÉLULAS}

Nas últimas décadas, pesquisas sobre a importância do levantamento dos conhecimentos prévios e sua aplicação no planejamento de ensino aumentaram consideravelmente, porém a maior parte dos estudos focou no âmbito do Ensino Fundamental e Médio (SILVEIRA, 2013; FELICETTI; PASTORIZA, 2015; BOZZA, 2016). Investigações que buscaram inferir e analisar os conhecimentos prévios de graduandos acerca de conteúdos do Ensino Superior no Brasil ainda são incipientes, e os que abordaram os conteúdos de Biologia Celular são escassos.

Legey et al. (2012) avaliaram os saberes sobre célula de alunos ingressantes em cursos superiores da área biomédica (Medicina, Medicina Veterinária, Enfermagem, 
Nutrição, Odontologia e Ciências Biológicas) e Galdino (2015) examinou as percepções por estudantes do primeiro semestre de Ciências Biológicas e ambos os estudos verificaram que os discentes não possuíam saberes prévios bem sedimentados na área de Biologia Celular. De forma geral, os autores apontaram que os alunos apresentaram diversas limitações em conceituar corretamente uma célula e atribuirIhe diferenciações, funções e dimensões, bem como em definir conceitos afins de maior complexidade.

Castro et al. (2016a, b) averiguaram os conhecimentos prévios científicos sobre ser vivo/célula de alunos do primeiro e terceiro semestre de um ciclo básico do curso de engenharia de pesca e identificaram um débito no conhecimento morfofuncional básico e sistêmico acerca da célula/organismo. Os autores argumentaram que essas lacunas poderiam ser reflexos do ensino na escola básica e não necessariamente retratavam limitações pessoais dos alunos.

E mais recentemente, Araújo Filho et al. (2019) investigaram o conhecimento prévio sobre Biologia Celular e Molecular de discentes de um curso de Agronomia e observaram que estes tendem a apresentar uma representação de célula com seu modelo estrutural mais simplista ilustrando apenas a membrana plasmática e nuclear. Este modelo é conhecido como modelo de ovo frito (descrito por YOREK; SAHIN; UGULU, 2010), e sua representação massiva na análise tende a indicar ser o reflexo do ensino resumitivo e também reducionista recorrente tanto nos materiais didáticos disponíveis para os alunos quanto nas explicações transmitidas pelos docentes.

Os estudos apresentados acima apontam uma fragilidade recorrente no conhecimento prévio por parte dos estudantes acerca do conteúdo de Biologia Celular e indicam que as falhas na formação conceitual precisam ser supridas na graduação a fim de direcionar e facilitar a ancoragem de novos conceitos. 


\section{MATERIAL E MÉTODOS}

O estudo quantitativo, descritivo e correlacional foi conduzido entre 2016 e 2017 com alunos do primeiro semestre do curso de enfermagem de uma instituição federal de ensino superior acadêmico. Os alunos foram apresentados aos objetivos e métodos de coleta da pesquisa, e um Termo de Consentimento Livre Esclarecido (TCLE) contendo as informações específicas foi distribuído e assinado pelos participantes ou representantes legais, no caso de participantes menores de idade. 0 TCLE solicitava a autorização para a reprodução dos dados para publicação preservando a identidade dos participantes, turma, instituição de ensino e quaisquer informações pessoais.

O teste de associação livre de palavras (TALP) foi utilizado para a coleta de dados para a análise do conhecimento prévio (ERCAN; TASDERE; ERCAN, 2010; KOSEOGLU; BAYIR, 2011; KURT, 2013). O método consiste em solicitar que os participantes indiquem um certo número de palavras ou termos sobre um determinado tema, sendo que a associação é livre. O número de palavras ou termos solicitados é de escolha do aplicador, porém é sugerido que o mínimo de palavras coletadas seja igual a cinco a fim de coletar uma amostragem tanto de termos consensuais quanto de termos diversificada (KURT et al. 2013).

Para a presente pesquisa, um questionário simples contendo 15 perguntas foi construído e dividido em duas partes: (I) contendo onze perguntas abertas e fechadas a fim de reunir informações sobre o perfil pessoal (idade e sexo) e educacional prévio (formação pública ou privada, e formação acadêmica anteriores); (II) uma pergunta aberta solicitando que o aluno citasse 10 palavras (por livre associação) correlacionadas sobre o tema "Célula". Após explicação do preenchimento, os questionários foram distribuídos e respondidos pelos participantes antes do início da disciplina. Os participantes tiveram 20 minutos para finalizar o questionário. 
Figura 1 - Fluxograma qualitativo para categorização inicial dos termos.



O número amostral de participantes foi de 60 alunos, onde 30 alunos eram da turma de 2016 e 30 alunos de 2017. Ao todo, cerca de 74\% dos participantes era composta pelo sexo feminino, com $26 \%$ de representatividade pelo sexo masculino. A idade das participantes femininas variou entre 16 e 38 anos, e entre 16 e 43 anos nos participantes masculinos. A idade média, para ambos os sexos, foi de 22 anos e com maior distribuição de participantes com idades entre 17 e 18 anos. Não foi objetivo proceder nenhum tipo de avaliação sobre diferenças entre respostas de discentes egressos de escola pública e particular.

Utilizou-se a amostragem por conglomerado, considerando as categorizações de termos centrais e derivados sobre o tema (SHAEFER; 1979; CASTRO et al. 2016b) de acordo com um fluxograma qualitativo elaborado com modificações para incluir as subclassificações Proximal e Distal (conceitos descritos na Figura 1), com a utilização de frequência simples e analisadas pelo Método de Análise de Conteúdo (MINAYO, 2000; BARDIN, 2010). Assim, inicialmente os termos foram elencados a partir do fluxograma qualitativo (Figura 1), e em seguida foram agrupados em categorias mais específicas criadas para realizar uma análise mais detalhada (ANGELINI; NETTO; ROSAMILHA, 2001) baseadas em categorias previamente apresentadas por França (2015) e Castro et al. $(2016 a, b)$. 


\section{RESULTADOS E DISCUSSÃO}

\subsection{Dados quantitativos}

Os participantes demonstraram conhecer diversos aspectos sobre o tema estudado. Ao todo, foram 210 termos associados, com 752 citações, sendo que todos os alunos apontaram ao menos um termo intimamente relacionado à célula. Os termos mais citados foram (número de citações/porcentagem): Núcleo (38/5\%), Membrana plasmática (32/4\%), Mitocôndrias (29/4\%), Ribossomos (26/3\%), Tecidos (24/3\%), Vida (23/3\%), DNA (21/3\%), Complexo de Golgi (21/3\%) e Citoplasma (21/3\%). Os demais 87 termos tiveram frequência de citações entre 19 e 2, e 114 termos foram citados apenas uma única vez.

A presença do grande número de termos era esperada visto que, em um levantamento feito por Carvalho, Nunes-Neto e El-Hani (2011), um aluno ao longo do Ensino Médio aprende cerca de 3.300 conceitos/termos novos. Porém a realidade é que o conhecimento nominal de um conceito ou termo não necessariamente significa a aprendizagem dos seus significados, sua compreensão da real aplicação na vida prática do aluno e suas diversas correlações contextuais (CASTRO et al., 2016b).

\subsection{Análise qualitativa}

A partir da análise dos termos, foram identificados 123 termos considerados centrais e 87 termos considerados derivados (com 29 proximais e 58 distais) (Figura 2). Assim, as seguintes categorias foram criadas para agrupar os termos centrais em conjuntos maiores (quantidade de termos agrupados/número de citações/porcentagem em relação ao número total de termos): (i) Categoria Estrutural, inclusos termos relacionados à composição molecular e estrutural das células (50/330/24\%); (ii) Categoria Funcional: relacionados às funções das células e subprodutos (51/113/24\%); e (iii) Categoria Descritiva, relacionados às características ou qualidades gerais das células 
(22/77/10\%). A categoria criada para os termos derivados proximais foi a Categoria Terminológica, acomodando palavras referentes a nomes de células, estruturas macros composta por células, áreas de estudos e outras palavras relacionadas mais diretamente às células (29/127/14\%); e para os termos distais foi a criada a Categoria genérica, acomodando palavras com conceitos muito amplos (58/109/28\%).

Figura 2 - Fluxograma qualitativo para categorização inicial dos termos



As categorias mais representadas, compreendendo ao todo $48 \%$ dos termos associados pelos alunos, foram a Estrutural e Funcional. Os três termos científicos mais associados à célula dentro dessas categorias foram: "Energia", "Divisão celular", e “Metabolismo" para a categoria Funcional (Figuras 3); e "Núcleo", "Membrana plasmática” e "Mitocôndrias" para a categoria Estrutural (Figura 4). A Categoria Descritiva foi a menos citada, representada por termos referentes às características intrínsecas como "Pequena", "Algo Pequeno", "Milhares" e "Muitas" relacionados com a dimensão e quantidade das células (Figura 5).

As categorias Estrutural e Funcional refletem as principais estruturas, composições, funções e conceitos recorrentemente estudados e citados ao longo do Ensino Fundamental e Médio, e correspondem aos conteúdos iniciais da ementa de Citologia. A 
atividade, função e composição celular são fundamentais para a introdução e aprofundamento do estudo das células, por estas serem a unidade básica da vida e centro de funções vitais que irão influenciar no equilíbrio orgânico humano, onde o desequilíbrio desse sistema pode levar ao surgimento de patologias.

Além disso, o conhecimento íntimo do funcionamento da célula é a base da compreensão da saúde e da doença, e é esperado que os alunos ainda durante o Ensino Fundamental e Médio sejam expostos a um certo aprofundamento dos processos e dinâmicas relativos aos dois temas, em especial por fazerem parte do dia-a-dia do aluno. Neste aspecto, foram também identificadas palavras associadas a termos médicos, como as patologias (incluídas na categoria Genérica), cuja correlação durante o curso de enfermagem é de extrema relevância, como "Doenças", "Anomalias", "Ferida" e "Câncer" (Figura 7).

A presença de termos referentes a elementos macroestruturais constituídos por células (“Corpo", “Estrutura”, “Tecidos", "Órgãos", "Ser vivo", "Sistemas", “Ser Humano”, "Pessoas" e "Organismo") e microestrutural presente nas células (como "Ácidos nucleicos", “Carboidratos", “Citoesqueleto", “Desmossomos", "Flagelo", “Fosfatidilserina”, "Fosfolipídios", "Glicocálix", "Interdigitações", "Microfilamentos" e "Microvilosidades"), compondo apenas $10 \%$ dos termos e também das frequências de citações, demonstrou que meramente uma pequena porção dos alunos consegue estabelecer níveis de compreensão macro e micro relacionado às células, que é um dos fatores fundamentais para a compreensão organizacional e espacial dos sistemas biológicos (BROWN; SCHWARTZ, 2009). E também reflete a falta de aprofundamento e abordagem multidisciplinar no ensino de base entre o conceito estrutural e sua função e processo fisiológico, que são fundamentais para a compreensão geral e dinâmica do organismo humano. 
Figura 3 - Termos e frequências associadas à célula na categoriza estrutural

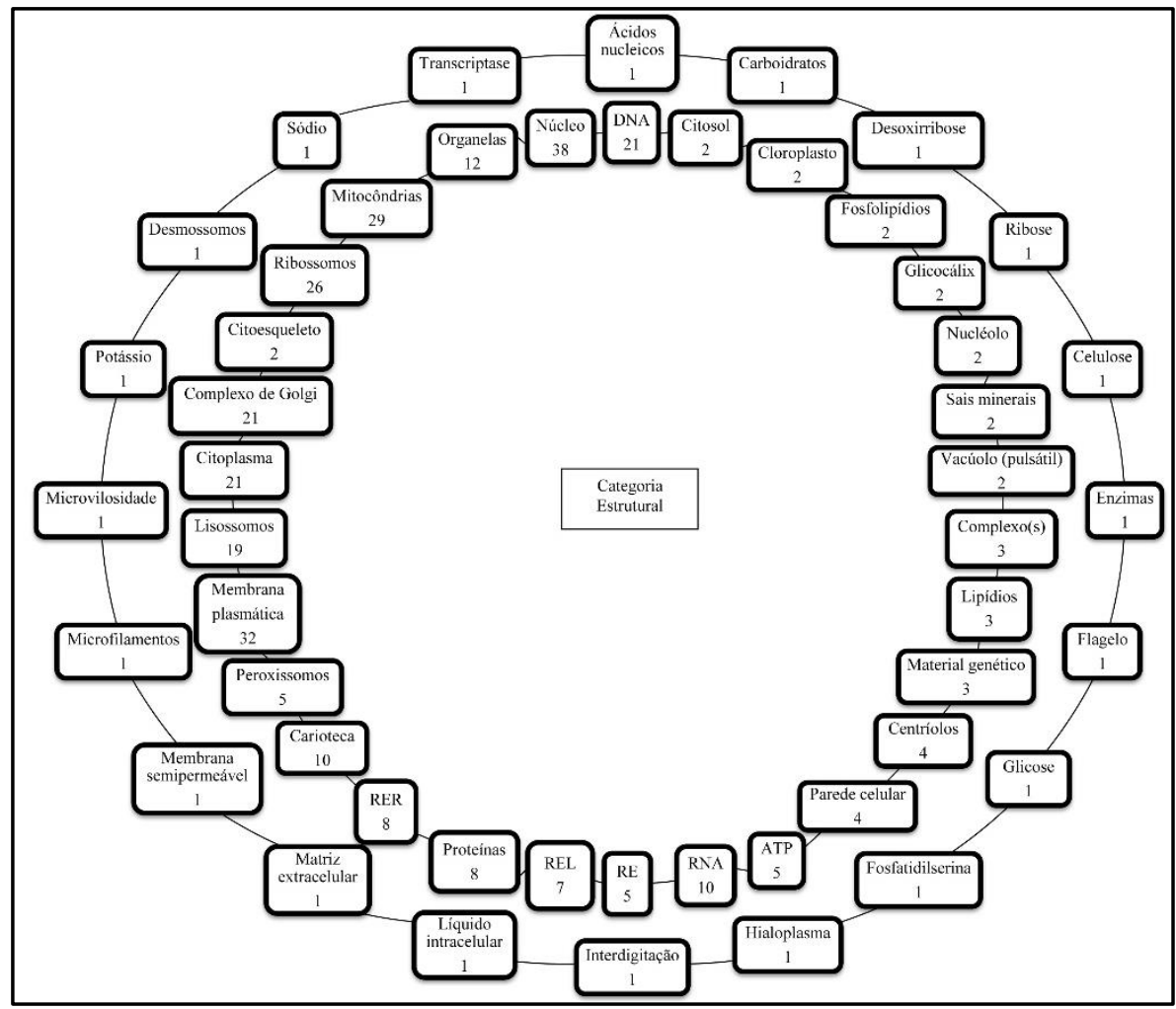

Figura 4 - Termos e frequências associadas à célula na categoriza funcional

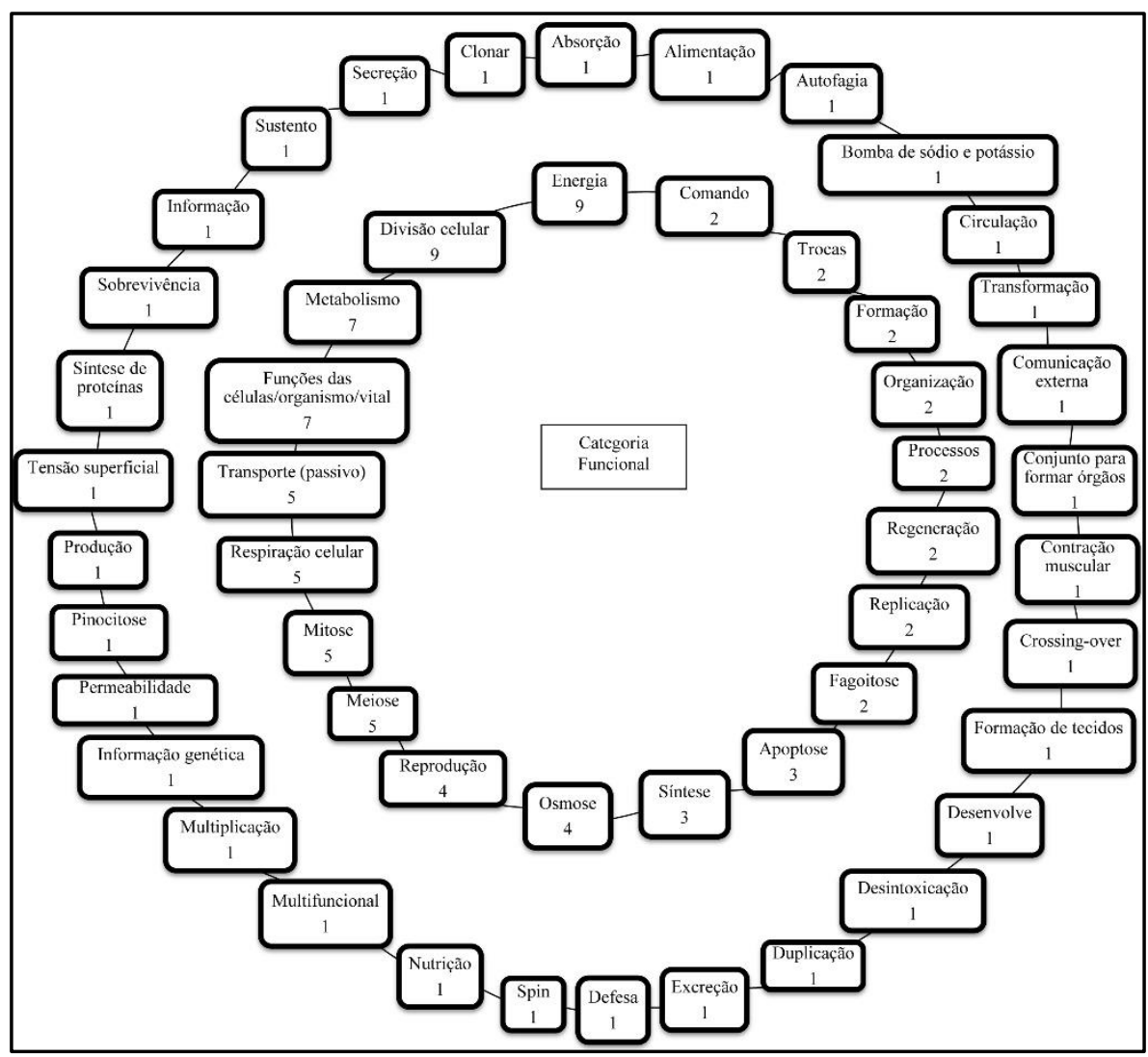


Figura 5 - Termos e frequências associadas à célula na categoriza descritiva

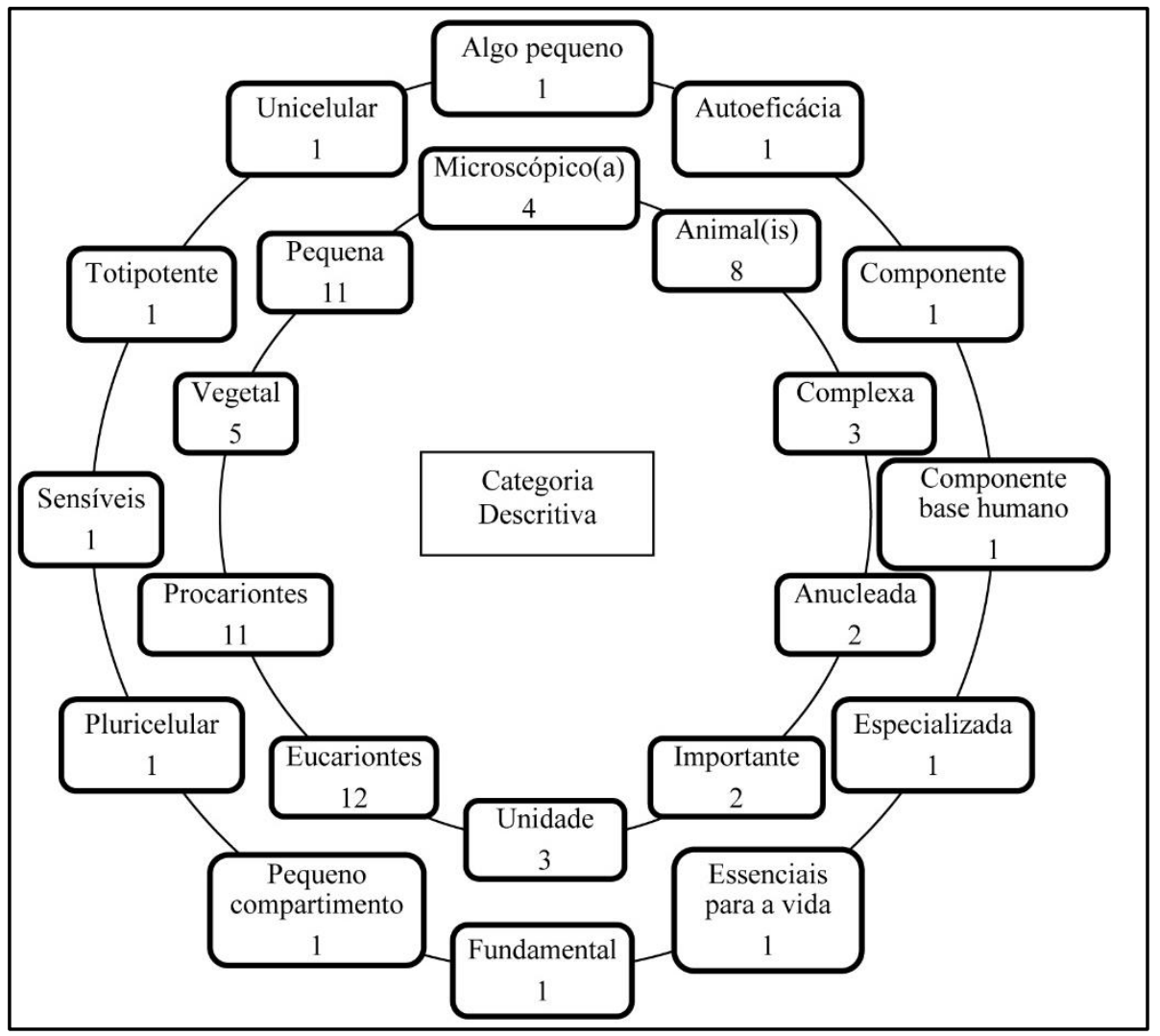

A categoria Terminológica compreendeu $14 \%$ dos termos associados pelos alunos, com "Tecidos", "Vida", e "Órgãos" como os três termos mais citados, e "Soluto", "Solvente" e "Receptores" como exemplos de palavras menos citadas (Figura 6). A categoria Genérica compreendeu 28\% dos termos, sendo "Microscópio", "Biologia", e "Vírus" os termos mais citados e "Planeta", "Cometa" e "Universo" como alguns dos termos menos citados (Figura 7). A prevalência de menos termos associados à categoria Terminológica, em comparação com a categoria Genérica, é um reflexo da visão reducionista e fragmentada da abordagem aos conteúdos relacionados à saúde e ao conteúdo estabelecido para as séries nos Ensino Fundamental e Médio (FREITAS; MARTINS, 2008).

A categoria Genérica também foi representada com termos como "Estudo", "Lâminas", "Laboratório" e "Pesquisa" (Figura 7). O progresso dos estudos celulares foi e está intimamente relacionado com o desenvolvimento de técnicas e equipamentos, ou seja, da instrumentalização física e de protocolos de pesquisas. Porém, é de conhecimento geral que a maior parte dos estudantes brasileiros não é exposta a aulas práticas ou experimentações com a utilização de instrumentos laboratoriais, tanto por 
falta de infraestrutura quanto por deficiências didático-pedagógicas dos professores, o que resulta na pouca familiaridade com os instrumentos de pesquisas mais usuais.

Batista et al. (2010) citam que a correta abordagem, tanto pelos professores quanto pelo material didático disponibilizado, é uma das dificuldades enfrentadas na construção da aprendizagem conceitual na Biologia, e é fundamental para proporcionar conhecimentos básicos e aplicados para serem utilizados no dia-a-dia dos alunos visando melhorar sua qualidade de vida no tocante à saúde coletiva, por exemplo.

Figura 6 - Termos e frequências associadas à célula na categoriza terminológica




Figura 7 - Termos e frequências associadas à célula na categoriza genérica

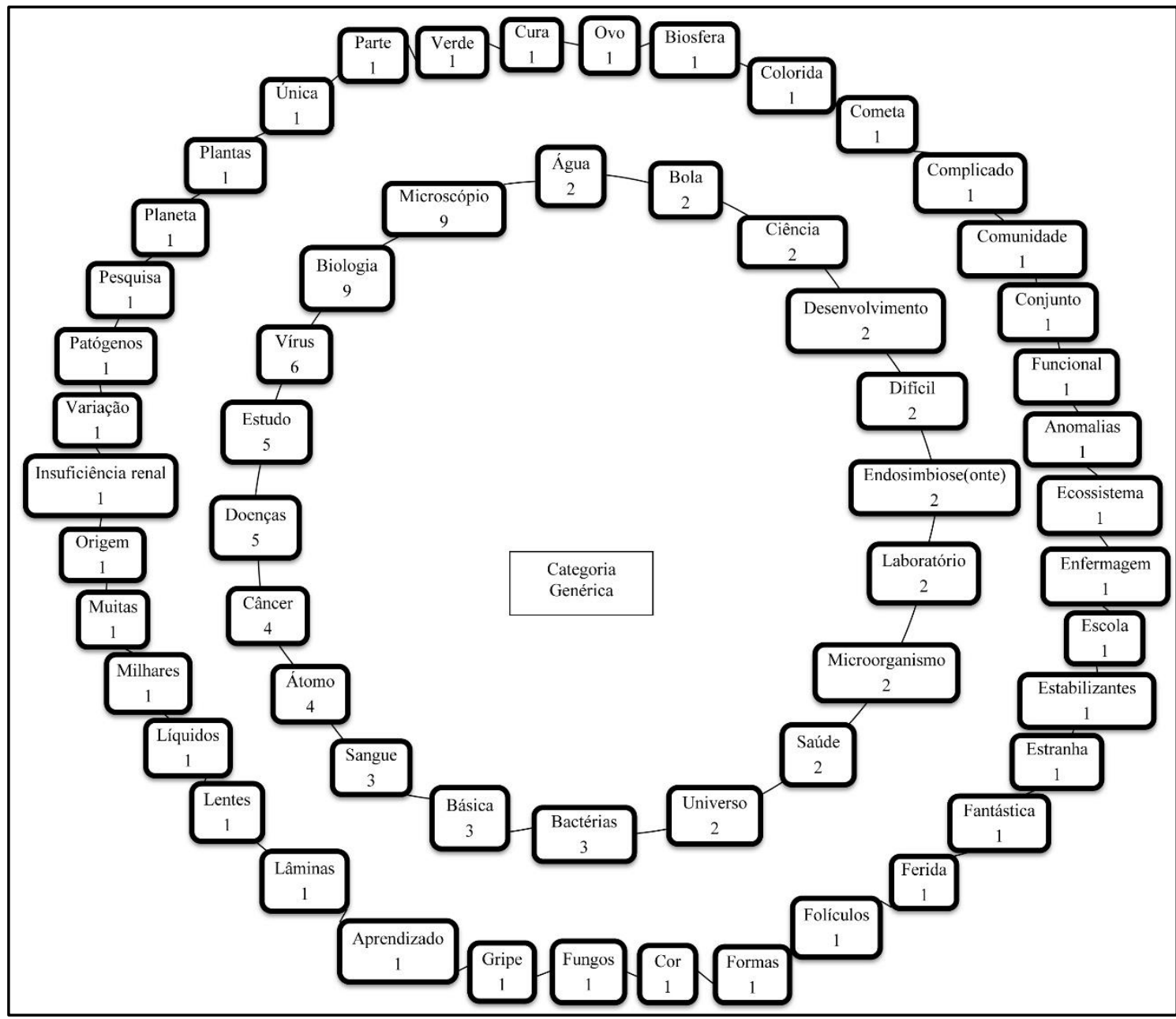

\subsection{Planejamento de ensino}

Com os dados verificados acima, pode-se concluir essencialmente que a maioria dos alunos apresentava familiaridade e possuía elementos básicos para o estudo das células (com 59\% dos termos identificados como centrais), porém a grande presença de termos derivados (41\%) e pouco contextualizados com os temas da saúde (agregados na categoria Genérica) indicou um baixo nível de conhecimento aprofundado, contextualizado e específico dos alunos. Essa análise é recorrente nos estudos de conhecimentos prévios no ensino de Biologia em geral, onde é esperada a presença de conhecimentos prévios rasos frutos de um ensino focado excessivamente na memorização de estruturas e funções biológicas, sem contextualização em relação aos processos de construção dos conhecimentos científicos (BASTOS, 1992; FOGAÇA, 2006, 
LIMA; TEIXEIRA, 2011), e com pouca ou nenhuma abordagem da aplicabilidade dos conteúdos de Biologia na vida cotidiana dos estudantes (LIMA; TEIXEIRA, 2011).

Ainda, Borges (1997) cita que as dificuldades de compreensão e de interpretação do mundo vivo, em especial com as dificuldades de contextualização e transposição de conceitos gerais para particulares, estão relacionadas aos problemas de conceitualização inicial apresentada no ensino de base, e aparecem em vários trabalhos destinados a investigar as representações dos alunos em aspectos distintos da Biologia e em diversos níveis de aprendizado. No geral, o ensino de Biologia, e suas áreas específicas como a Citologia, são desenvolvidos com foco na memorização de conceitos, termos, estruturas e funções, ou seja, com práticas de ensino sem contextualização e aplicabilidade, fortalecendo o desinteresse dos alunos pelos temas relacionados à Ciência. Assim, cabe ao professor ter ampla consciência do seu papel e desenvolver suas práticas e estratégias de ensino a fim de minimizar as dificuldades encontradas em sala de aula.

Uma das formas de promover efetivamente o aprendizado de um novo conteúdo é a construção de um planejamento adequado de ensino, e é recorrente nos debates atuais sobre o processo de ensino-aprendizagem de Ciências a necessidade de conceber o estudante como ponto de partida para essa construção. Nessa perspectiva, a consideração dos conhecimentos prévios que os estudantes carregam consigo para a sala de aula é o primeiro passo para a construção das estratégias de ensino. Dessa forma, observando a análise realizada e buscando um planejamento de ensino a partir dos dados, a estratégia de ensino inicial buscou tanto a ativação do conhecimento prévio dos alunos quando o nivelamento conteudinal da turma com a revisão dos conceitos básicos gerais abordados no ensino básico, antes do aprofundamento do conteúdo exigido pela disciplina.

Durante as aulas buscou-se sempre correlacionar os conceitos e processos básicos com os termos clínicos mais citados (que serão constantes e fundamentais na formação profissional), interdisciplinarizar com métodos de investigação que farão parte das aulas práticas e nas funções corriqueiras laboratoriais enquanto enfermeiros formados e subsidiar uma abordagem contextual com o dia-a-dia dos alunos e com suas demais práticas profissionais futuras. Por exemplo, ao apresentar a estrutura básica da célula foi trabalhada a grande variação das formas das células dependendo da sua 
função no organismo (como a forma normal arredondada das hemácias do sistema sanguíneo, que melhor permite o seu transporte na corrente sanguínea, em contraste com a forma estrelada dos astrócitos do sistema nervoso, que permite um maior raio de alcance da sua membrana plasmática), e também o impacto da alteração da forma da célula que pode resultar em doenças (como na Anemia Falciforme, que é caracterizada pela forma anormal das hemácias, onde o formato anormal de foice prejudica a sua circulação na corrente sanguínea).

Além disso, durante as aulas foram incluídas informações baseadas em termos não citados, como os que indicassem tipos de procedimentos médicos e medicamentos, e aqueles relativos à Bioética que corresponderiam às questões éticas como experimentos humanos e com uso de outros animais.

A estratégia de iniciar o conteúdo a partir de pontos conhecidos permitiu a maior assimilação pelos alunos, pois funcionou como ponto de ancoragem para que eles relembrassem elementos conhecidos, e influenciou positivamente na incorporação de novas informações. Essa abordagem é consoante com a Teoria Histórico-Cultural de Vygotsky, que exalta a abordagem sistêmica para o ensino dos conceitos a partir dos conhecimentos prévios dos universitários (VYGOTSKY 1991, 2010). A abordagem contextual também potencializou aulas mais reflexivas e participativas dos alunos, possibilitando a motivação dos estudantes em correlacionar os conceitos científicos com seu cotidiano e facilitando a compreensão dos conceitos em geral.

\section{CONCLUSÕES}

O presente trabalho investigou o conhecimento prévio de alunos sobre o tema "Célula" que resultou em um grande número de termos demonstrando que os estes conheciam diversos aspectos relevantes sobre o tema com 210 termos e 752 citações ao todo. A análise dos termos a partir das categorias criadas permitiu o planejamento de ensino buscando o conhecimento sistematizado partindo dos conhecimentos prévios dos alunos e de uma abordagem contextualizada, tanto correlacionando com a vida cotidiana do aluno quanto com conhecimentos fundamentais para a formação do profissional. 
Assim, é possível concluir que o levantamento do conhecimento prévio dos estudantes é fundamental na construção do planejamento de ensino do professor, pois ajuda na elaboração de roteiros de aulas que promovam o nivelamento inicial da turma, ativação de outros conhecimentos prévios, identificação de outras dificuldades conceituais e aprofundamento sistematizado do conteúdo.

O resultado obtido aqui corrobora com os demais trabalhos e, apesar dessa prática de levantamento do conhecimento prévio no âmbito da Educação Superior nas áreas biológicas ser ainda preambular, revela que grande parte dos alunos ingressantes na graduação possui importantes deficiências de saberes que podem ter impacto negativo na construção pedagógica desse futuro profissional e na formação acadêmica progressiva.

E finalmente, com relação ao método de levantamento de conhecimento prévio, a avaliação de associação de palavras pode fornecer aos professores as formas e níveis de saberes prévio dos alunos, permitindo auxiliá-los no desenvolvimento e no aprofundamento dos conteúdos das disciplinas. O método também pode resultar na identificação de assuntos não abordados durante o ensino básico e omissos no currículo acadêmico, suprindo lacunas conteudinais importantes.

\section{AGRADECIMENTOS}

Ao Programa Nacional de Pós Doutorado da Coordenação de Aperfeiçoamento de Pessoal de Nível Superior (PNPD/CAPES) através do Programa de Pós-Graduação em Educação da Universidade Estadual de Roraima (UERR).

\section{REFERÊNCIAS}

ANGELINI AL, NETTO SP, ROSAMILHA N. Análise de conteúdo da psicologia educacional: Psicologia escolar Educacional. Campinas. 2001,5(1):83- 90.

AUSUBEL DP. Educational Psychology: A cognitive view. New York: Holt, Rinehart and Winston. 1990.

BARDIN L. Análise de conteúdo. 4. ed. Lisboa: Edições70. 2010. 
ARAUJO FILHO JCPJ, MIRANDA TM, JAPPE S, DODE LB, ROCHA BHG, BOBROWSKI VL. Célula: investigando conhecimentos prévios de universitários. In: $5^{a}$ Semana Integrada UFPel/SIIEPE - V CEG, 2019, Pelotas. 5a Semana Integrada UFPel/SIIEPE - V CEG. 2019.

BASTOS FO. Conceito de célula viva entre alunos do segundo grau. Em Aberto (Brasília). 1992,11(55).

BATISTA MVA; CUNHA MMS; CANDIDO AL. Análise do tema virologia em livros didáticos de biologia do ensino médio. Ens. Pesqui. Educ. Ciênc. (Belo Horizonte), 2010,12(1):145-158.

BORGES EL. Os mapas conceituais como facilitadores da aprendizagem significativa em Biologia Celular. In: Atas do Primeiro Encontro Nacional de Pesquisa em Ensino de Ciências. Águas de Lindóia. 1997.

BOZZA EC. Entrando no ensino médio: caderno de avaliação diagnóstica de conteúdos em biologia. Produto educacional (Mestrado em Ensino de Ciências) - Pós-Graduação em Formação Científica, Educacional e Tecnológica, Universidade Tecnológica Federal do Paraná, Paraná. 2016.

BRASIL. Ministério da Educação. Base Nacional Comum Curricular. Proposta preliminar. Segunda versão revista. Brasília: Ministério da Educação. 2016.

BRASIL. Ministério da Educação. Ciências da natureza, matemática e suas tecnologias/ Secretaria de Educação Básica. - Brasília: Ministério da Educação, Secretaria de Educação Básica, 2006. 135 p.

BROWN MH, SCHWARTZ RS. Connecting photosynthesis and cellular respiration: Preservice teachers' conceptions. J. Res. Sci. Teach. 2009,46:791-812.

CARVALHO IN, NUNES-NETO NF, EL-HANI CN. Como selecionar conteúdos de biologia para o ensino médio? ver. Ed. Ciên. Mat. 2011,1(1):67-100.

CASTRO DR, GUERRA JA, SANTOS KB, SANTOS NP, SANTOS SRM, AMORIM TS. As concepções sobre Ser Vivo/Célula dos Estudantes do $3^{\circ}$ semestre do Curso de Engenharia de Pesca do Campus XXIV- Xique-Xique-BA. Revista Brasileira de Ensino de Ciência e Tecnologia, 2016a, 9:301-325.

CASTRO DR. GUERRA JÁ, SANTOS NP, SANTOS SEM, AMORIM TS, SANTOS K B. Os conhecimentos prévios sobre ser vivo/célula dos estudantes ingressos no curso de engenharia de pesca. Ens. Pesq. Educ. Cien. (Online). 2016b, 18: 73-96.

ERCAN F, TASDERE A, ERCAN N. Observation of cognitive structure and conceptual changes through word associations tests. J. Turk. Sci. Educ. 2010,7(2):138-154.

FELICETTI SA, PASTORIZA BS. Aprendizagem Significativa e Ensino de Ciências Naturais: um levantamento bibliográfico dos anos de 2000 a 2013. Aprendizagem Significativa em Revista. 2015,5(2):1-12.

FOGAÇA M. Papel da inferência na relação entre os modelos mentais e modelos científicos de célula. Dissertação (Mestrado) - Ensino de Ciências e da Matemática, Faculdade de Educação da Universidade de São Paulo, São Paulo. 2006. 
FRANÇA JAA. Ensino-aprendizagem do conceito de "célula viva": proposta de estratégia para o ensino fundamental. Dissertação (Mestrado em Ensino de Ciências) - Universidade de Brasília, Brasília. 2015.

FREITAS EO, MARTINS I. Concepções de saúde no livro didático de ciências. Rev. Ensaio. 2008,10(2):235-256.

GALDINO TRR. Percepção a respeito da célula apresentada por estudantes do primeiro semestre do curso de ciências biológicas. Monografia: Universidade Federal da Paraíba. 2015. p.15.

GILBERT JK, BOULTER C, RUTHERFORD M. Models in explanations, part 1, Horses for courses? Int. J. Sci. Educ. 1998a;20:83-97.

GILBERT JK, BOULTER C, RUTHERFORD M. Models in explanations, part 2, Whose voice? Whose ears? Int. J. Sci. Educ. 1998b;20:187-203.

GILBERT JK, BOULTER CJ. Learning science through models and modeling. In: Tobin K, Frazer B, editors. The international handbook of science education. Dordrecht: Kluwer; 2000.

KOSEOGLU F, BAYIR E. Examining cognitive structures of chemistry teacher candidates about gravimetric analysis through word association test method. Trakya Uni. J. Educ. Fac. 2011;1(1):107-125.

KURT H. Biology student teachers' cognitive structure about "Living thing". Educ. Res. Rev. 2013;8(12):871-880.

KURT H, EKICI G, AKTAS M, AKSU O. Determining biology student teachers' cognitive structure on the concept of "diffusion" through the free word-association test and the drawing-writing technique. Int. Educ, Stud. 2013;6(9).

LEGEY AP, CHAVES R, MÓL ACA, SPIEGEL CN, BARBOSA JV, COUTINHO, CMLM. Avaliação de saberes sobre célula apresentados por alunos ingressantes em cursos superiores da área biomédica. REEC, 2012;11(1):203-224.

LIMA GPS, TEIXEIRA PMM. Análise de uma sequência didática de Citologia baseada no Movimento CTS. Atas do Encontro Nacional de Pesquisa em Educação em Ciências. Campinas: Associação Brasileira de Pesquisa em Educação em Ciências; 2011.

MINAYO MCS. O Desafio do Conhecimento. 7. edição. São Paulo - Rio de Janeiro: Hucitec Abrasco. 2000.

SALVATIERRA L. Aplicação do método de desenho associado à escrita para determinação do conhecimento prévio. Rev. Electrón. Enseñ. Cienc. 2019,19:159-176.

SHAEFER G. Concept Formation in Biology: The Concept "Growth". Eur. J. Sci. Educ., 1979, 1(1).

SILVEIRA ML. Dificuldade na aprendizagem e percepções alternativas em biologia: a visão de professores em formação sobre o conteúdo de citologia. 2013. 197 F. Dissertação (Mestrado) - Universidade Federal do Rio Grande do Norte, Natal. 2013. 
VYGOTSKY LS. A Construção do Pensamento e da Linguagem. 2. ed. São Paulo: Martins Fontes. 2010.

VYGOTSKY LS. Pensamento e linguagem. São Paulo: Martins Fontes. 1991.

YOREK N, SAHIN M, UGULU I. Students' representations of the cell concept from 6 to11 grades: Persistence of the "fried-egg model". Int. J. Phys. Sci. 2010, 5(01):15-24.

\section{Contribuições de autoria}

\section{1 - Lidianne Salvatierra}

Mestre e Doutora em Ciências Biológicas pelo Instituto Nacional de Pesquisas da Amazônia. Tem Pós-Doutorado em Educação, através do Programa Nacional de Pós Doutorado da CAPES pela Universidade Estadual de Roraima. Atualmente é Professora Adjunta I e coordenadora do curso de Biologia da Universidade Federal de Tocantins. https://orcid.org/0000-0002-2479-9924 - lidiannetrigueiro@gmail.com Contribuição: Responsável pelo projeto, participou de todo planejamento, execução e confecção do manuscrito.

\section{Como citar este artigo}

SALVATIERRA, L. Utilizando os conhecimentos prévios sobre célula de estudantes de um curso de enfermagem como ponto de partida do planejamento de ensino. Ciência e Natura, Santa Maria, v. 43, e28, p. 1-22, 2021. Disponível em: https://doi.org/10.5902/2179460X32483. Acesso em: dia, mês (abreviado), ano. 